of the type of the distribution $\left\{I_{h}\right\}$ than the half-peak width as already discussed earlier (Ruland, 1967).

An average value of $0.65( \pm 0.03)$ was found for the slope parameter as defined above. The corresponding values are 0.773 for a Gaussian distribution, 0.798 for circular discs and 0.591 for a Cauchy distribution.

Finally, the average $\mathrm{C}-\mathrm{C}$ bond length has been calculated from the correct $s_{h}$ values obtained by the minimization of the initial slope of $B_{h}$ as discussed above. The values are increasing smoothly from $1.416 \AA$ for the $2000^{\circ} \mathrm{C}$ sample to $1.418 \AA$ for the $3000^{\circ} \mathrm{C}$ sample with an error limit of $\pm 0.0005 \AA$. These values are well below the $\mathrm{C}-\mathrm{C}$ bond length in graphite (1.421 $\AA$; Bacon, 1950) and correspond to the average $\mathrm{C}-\mathrm{C}$ bond lengths found in aromatic molecules with 5-10 rings. It is, however, possible that the low value is due to a non-planarity of the layers which can produce an apparent decrease of the twodimensional lattice parameters.

In conclusion one can state that the main reason for the stability of the non-graphitic and non-graphitizing state of carbon is the fact that no appreciable layer growth occurs at higher temperatures although the layer structure becomes gradually more perfect. This suggests that it is the layer growth at temperatures below $2000^{\circ} \mathrm{C}$ which conditions the graphitization and that the elimination of imperfections in the layer structure only leads to a three-dimensional ordering when the layer size exceeds a critical limit.

\section{References}

Bacon, G. E. (1950). Acta Crvst. 3, 137.

Bouraoui, A. \& Méring, J. (1963). Carbon, 1, 465.

Bertaut, E. F. (1950). Acta Cryst. 3, 14.

Clarke, J. S. (1964). Private communication reported by Warren \& Bodenstein (1966).

Keating, D. T. \& Warren, B. E. (1952). Rer. Sci. Instrum. 23, 519.

Ruland, W. (1967). Acta Cryst. 22, 615.

Warren, B. E. (1941). Phy's. Ret. 59, 693.

Warren, B. E. \& Averbach, B. L. (1950). J. Appl. Phys. 21, 595 .

Warren, B. E. \& Bodenstein, P. (1966). Acta Cryst. 20,602.

\title{
Notes and News
}

Announcements and other items of crystallographic interest will be published under this heading at the discretion of the Editorial Board. The notes (in duplicate) should be sent to the General Secretary of the International Union of Crystallography (G. Boom, Laboratorium voor Fysische Metaalkunde der Rijksuniversiteit, Universiteitscomplex Paddepoel, Groningen, The Netherlands). Publication of an item in a particular issue cannot be guaranteed unless the draft is received 8 weeks before the date of publication.

\section{Conference on Crystal Growth 11-13 August 1969, Washington D.C., U.S.A.}

The American Committee for Crystal Growth will sponsor a conference on Crystal Growth to be held at the National Bureau of Standards near Washington D.C., U.S.A. on 11 to 13 (inclusive) August 1969. The meeting will encompass all aspects of the theory and practice of crystal growth. Sessions will be held which are especially devoted to impurity distribution; new results in growth from vapour, from the melt and from solution; polymers, including selenium and tellurium; eutectics, dendrites and morphological stability.

Two-hundred word abstracts for fifteen-minute contributed papers should be submitted before 1 May 1969, to

C.S. Sahagian, Conference Secretary,

U.S. Air Force Cambridge Research Laboratories,

L.G. Hanscom Field, Bedford, Massachusetts 01730, U.S.A.

The subjects and speakers for invited papers will be announced at a later date. For further information, write to the Conference Secretary. 